Área Abierta. Revista de comunicación

audiovisual y publicitaria

ISSN: 2530-7592 / ISSNe: 1578-8393

http://dx.doi.org/10.5209/ARAB.60176

\title{
Representación de la crisis
}

Presentación: María José Revuelta

Desde la implantación a nivel mundial de la globalización en los años noventa, las crisis ambientales, sociales y políticas se han ido sucediendo de forma periódica y con consecuencias cada vez más complicadas de solventar: México (1994), crisis asiática de 1997-1998 (con causas muy semejantes a la actual generada en 2008), Brasil (1999), Rusia (1998-1999), Turquía, Argentina (2001-2002). La crisis iniciada en Estados Unidos y que ha mutado en la Gran Recesión en el año 2008 por tratarse de una crisis económica mundial, continúa vertiendo sus efectos. Crisis recurrentes y admitidas por los ciudadanos resignados a acatar la austeridad impuesta por el Consenso de Washington, decálogo inamovible de la globalización y que ha convertido la economía en un casino mundial. Son las consecuencias de pervertir la naturaleza y función primigenia del capital financiero -invertir en la producción y la innovación tecnológica- hacia la especulación. Es lo que muchos investigadores denominan desde hace décadas capitalismo de casino. La Gran Recesión se extiende como crisis política, social energética, ambiental; y de forma más esencial, individual y emocional.

La sensación generalizada en los ciudadanos es que las pérdidas del sector financiero se socializan bajo el temor de una desestabilización mayor del orden económico global que agrave las consecuencias. El cine, la publicidad, la información audiovisual y escrita que circula por las redes globales, simultáneamente creadores y reflejo de imaginarios sociales, nos ofrecen un balance sobre cómo el sistema de creencias y representaciones mentales surgidas de la crisis se integra en las condiciones reales de existencia de los ciudadanos.

Como todos los sistemas, la globalización no es uniforme, se propaga a diferentes velocidades en los distintos países del planeta y se ejercen fuerzas contrapuestas al proceso de interdependencia económica, política y cultural. En el Líbano, Hasan Nasrallah, líder político-religioso de Hezbollah construye una imagen pública omnipotente sobre la persuasión, el enemigo común y el control de la violencia en esquemas comunicativos tradicionales. En países occidentales se ganan campañas electorales utilizando sofisticados tratamientos de Big Data, que se extraen de las redes sociales, y que son capaces de interpretar el componente emocional subyacente en el lenguaje.

Desde los inicios del siglo XX, se había entendido en los países capitalistas, que era más sencillo conquistar la imaginación de la población, que es la capacidad que nos hace conscientes de nosotros mismos y con la cual creamos razones y fines para nuestra vida, que controlar a la gente por la fuerza. Y este hecho, junto con la importancia de las emociones y los sentimientos en la toma de decisiones, bien 
conocido y utilizado en la publicidad y la industria de las relaciones públicas, es refrendado por la ciencia sobre todo desde el espectacular desarrollo de las ciencias cognitivas a partir de los años noventa del pasado siglo. La publicidad comercial nos ofrece una felicidad espuria, o cuanto menos, efímera a través del consumo. Una de las estrategias para continuar legitimando la ideología neoliberal dominante en esta época de crisis y crear vínculos emocionales con las marcas, es desviar el foco hacia el ámbito individual y anestesiar el debate sobre las causas y los culpables de la crisis. Aparece la crisis como oportunidad, como catarsis del individuo que conducirá finalmente, mediante el espíritu de superación y el sentido del humor, a una transformación personal que lleva al disfrute de la cotidianidad y el presente.

El cine ha reflejado desde los años noventa la crisis del hombre posmoderno. La construcción del héroe busca la identificación de este arquetipo entre el público masculino, hombre común no adaptado al sistema e insatisfecho de sus relaciones personales pero que mantiene el orden y la justicia enfrentándose al prototipo de triunfador, culto, ególatra y de clase alta. También en otros géneros como el cine de autor, el cine de realidad o el múltiplex los protagonistas se ubican en un ambiente de soledad y de deterioro de las relaciones afectivas donde resulta habitual el aislamiento y la agresividad. Es la batalla social, económica y también moral del hombre postmoderno que supera el planteamiento maniqueo. Y los desenlaces muestran al hombre apático hacia el mundo, que se vuelca en sí mismo en una situación de catástrofe aceptada y desencanto donde la incertidumbre parece dominar el pensamiento.

Además, surgen autores que muestran esperanza y aventuran cambios, como la necesidad del hombre posmoderno de volver a sentir y buscar de manera pragmática un ideal. Muestra de ello es la priorización de los valores sociales y humanos, el equilibrio sostenible y los avances en el feminismo, enmarcados en el replanteamiento de prosperidad que expone la narrativa de las grandes producciones del sueño espacial. También resulta esperanzador y representativo a este respecto el acuerdo entre dos corrientes históricamente enfrentadas, en el posicionamiento ético y en las características morales y estéticas para narrar un acercamiento a la verdad y a la memoria en uno de los grandes genocidios del siglo XX en El hijo de Saúl.

Todo este mosaico de representaciones de la crisis, podría ser un ejemplo sobre cómo el sistema capitalista neoliberal en su última fase fagocita el concepto de crisis y sus consecuencias mediante un acto de racionalismo espurio (racionalización). O quizás supongan los inicios de la dolorosa gestación de un nuevo modelo de pensamiento. 